\title{
Profile of Deficits on Assessment Battery in Children with Specific Learning Disorders
}

\author{
${ }^{1}$ Adarsh Kohli, ${ }^{2}$ Aditi Sharma, ${ }^{3}$ Susanta K Padhy
}

\section{ABSTRACT}

Learning disabilities affects the acquisition, organization, retention, understanding, or use of verbal or nonverbal information. They usually result from impairments in memory, attention, phonological processing, language processing, visuospatial processing, and so forth leading to inabilities in oral language like speaking and understanding the grammatical constructions, reading like phonetic knowledge and word recognition, written language like spellings and alphabet recognition, and also arithmetic like computation.

The aim of the current study is to show the profile in learning disabled children.

Brigance Basic Skills List and the National Institute of Mental Health and Neurosciences (NIMHANS) index of specific learning disabilities are used for the purpose. The Brigance Basic Skills List is designed to assess visuomotor skills, visual discrimination, acquisition of gross motor and fine motor skills, and acquisition of alphabets and numbers. The NIMHANS index in addition to the above also assesses the reading, writing, spellings, and arithmetic skills of the subjects and other functions like attention, memory, and perceptual motor functions of the subjects. The sample was drawn from the Child and Adolescent Psychiatric clinic of outpatient of Department of Psychiatry, Postgraduate Institute of Medical Education and Research, Chandigarh, India. It comprised of 20 subjects within the age range of 10 to 18 years with learning disabilities in one or more areas along with difficulties. They were all belonging to middle- to upper-middle socioeconomic status and were studying in private school setup.

The results show the profile of the subjects on attention in terms of distractibility and impulsiveness, the memory profile, perceptual motor functions, basic academic skills in terms of visual and auditory discrimination, concept and sequencing of letters and numbers, and the type of errors in terms of their reading, writing, spellings, and arithmetic skills.

Keywords: Attention, Disability, Learning, Memory.

How to cite this article: Kohli A, Sharma A, Padhy SK. Profile of Deficits on Assessment Battery in Children with Specific Learning Disorders. J Postgrad Med Edu Res 2018;52(3):120-127.

Source of support: Nil

Conflict of interest: None

\footnotetext{
${ }^{1}$ Professor, ${ }^{2}$ Assistant Clinical Psychologist, ${ }^{3}$ Additional Professor

${ }^{1-3}$ Department of Psychiatry, Postgraduate Institute of Medical Education and Research, Chandigarh, India

Corresponding Author: Adarsh Kohli, Professor, Department of Psychiatry, Postgraduate Institute of Medical Education and Research, Chandigarh, India, e-mail: doc_adarsh@hotmail.com
}

\section{INTRODUCTION}

The human brain is endowed with the capacity to sense, attend, perceive, and comprehend. When all these faculties of brain function adequately, learning takes place. However, when there are disturbances in this sequence of events, there occurs a disturbance to learning as well, which could be understood as a manifestation of learning disorders. ${ }^{1}$

Learning problems many a times are amiss for various other behavioral problems and thus are not adequately diagnosed. Learning disabilities refer to a number of conditions that might affect the acquisition, organization, retention, understanding or use of verbal and non verbal information. These disorders affect learning in individuals who otherwise demonstrate at least average abilities essential for thinking and/or reasoning. As such, learning disabilities are distinct from global intellectual disabilities. Learning disabilities result from impairments in one or more processes related to perceiving, thinking, remembering or learning. These include, but are not limited to language processing, phonological processing, visuospatial processing, processing speed, memory, attention and executive functions (e.g., planning and decision making). ${ }^{1}$

Identifying a learning disability is a crucial task and should be done with utmost precision assessing all the aspects that might be hindering the child from performing well at school. Usually signs of learning disorders are not detected until a child is put in school and is meant to read and write. However, when traced in retrospect there are certain subtle signs that start showing and are almost common to all learning disability children and thus can be generalized.

The learning disorders should not be confused with conditions, such as lack of opportunity to learn. Rather, these disorders are thought to stem from abnormalities in cognitive processing that derive largely from some kind of biological dysfunction. They are not a direct result of other disorders, such as mental retardation, gross neurological deficits, uncorrected visual or auditory problems, or emotional problems. ${ }^{2}$ Thus, all these need to be ruled out before a diagnosis of learning disorder is formulated. Social or economic disadvantage has been mentioned as an exclusionary criterion for the diagnosis of learning disorders. ${ }^{3}$ Thus, these abovementioned factors fall out of the purview of learning disorders. 
A consistent inability to perform age appropriately is usually an alarming sign for parents wherein they seek help. Thus, the discrepancy level between the class placement and the achievement level seems to be an adequate indicator of learning problems if all the aforementioned factors have been ruled out. For example, if a child placed in standard $\mathrm{V}$ is able to function only until standard II then it is suggestive of learning problems. Other subtle indicators include deficits in visual and auditory discrimination, visual and auditory memory, verbal expression, and further conceptualization of the written expression, perceptual motor skills, developmental delays particularly speech delay, attention deficits, deficits in sequencing of numbers and alphabets, which are considered to be the basic units of written expression and working memory deficits.

Specifically, in the domain of language there could be deficits in handling complexity, such as confusions while listening to a long conversation, deficits in adaptive and flexible functioning, such as inability to express self in different ways to be understood and also difficulty in noticing typical language, form, and language. In the domain of visual deficits, tendencies of forgetting how alphabets or words look or are spelled, inability to differentiate between letters looking alike, e.g., p, q, making wild guesses while reading words. In terms of arithmetic difficulties in grasping the concepts, such as $4 \times 4$ is same as 20 to 24 or $8 \times 2$, difficulties in noticing differences between the signs of addition and multiplication have been reported. Certain deficits in practical abilities, such as inability to pre-plan time, various social deficits, and deficits in knowledge of body have also been enumerated. ${ }^{4}$

Specific learning disorders (SLDs) seem to affect all domains of a child's life including academic, emotional, social, and behavioral. The target of SLD assessment should not be a "label" for the child per se but lending a helping hand in order to help the child in overcoming the difficulties. Thus a thorough assessment procedure must be followed focusing on intelligence level, information processing abilities including gross motor abilities, fine motor abilities, sequential memory, working memory tasks, attention, emotional and behavioral difficulties, readiness to go to school and study, classroom and parents observation of learning behaviors, hand eye coordination, and organizational abilities.

Specific learning disorder goes undetected in many children in Indian society and is attributed to poor compliance of children to teacher's instructions, defiance, inattention, lack of interest in studies, and so on there by affecting the child's emotional and social well being. It is estimated that about $10 \%$ of children in India have learning problems out of which $4.6 \%$ are severely learning disabled. ${ }^{3}$ On similar lines, a recent study has estimated that learning disability is present in about $3 \%$ of thirdand fourth-grade students assessed from a cross-sectional sample. ${ }^{5}$ It has been evidenced that usually children with learning disorders have the characteristics, such as attention and concentration difficulties, socialization difficulties, low frustration tolerance, perceptual difficulties, hyperactivity, poor in reading, writing, spellings, and arithmetic. ${ }^{6}$

Keeping in mind the abovementioned information, it was thought imperative to explore a pattern of deficits in children suffering from SLDs (mixed type) if any, in order to aid in early detection and early remedial process. Thus, this study was undertaken with the following research purposes in mind:

- To assess the pattern of errors in reading, writing, spellings, and arithmetic skills in SLD children.

- To assess the pattern of deficits in attention, memory, perceptual-motor functions, and basic academic skills in SLD patients.

\section{MATERIALS AND METHODS}

\section{Sample}

The study comprised of 20 subjects from Child and Adolescent Psychiatry clinic diagnosed with specific learning disability (mixed type) by a consultant psychiatrist (International Classification of Diseases-10 criteria) and objectively assessed on the NIMHANS SLD battery. ${ }^{7}$ The subjects recruited were within the age range 10 to 18 years. The sample consisted of both the genders belonging to middle- and upper-middle socioeconomic status. Children with an intelligence quotient $(\mathrm{IQ})<70$, epilepsy, head injury, and infection were excluded from the study.

\section{Tools}

The following tools were used:

- Speed and Accuracy Test ${ }^{8}:$ It is a mental fatigue test in which the speed and accuracy of a child on an attention task is checked. It has two levels of complexity, i.e., level I encircling four alphabets C, T, P, and S. Level II of the test requires the subject to encircle any two numbers that make up a sum of 10 . However, in our study group, since these children were clinically diagnosed with learning disabilities we modified the two levels of complexity. Level I in our study comprised of encircling the number 4 and level II comprised of encircling two alphabets $\mathrm{C}$ and T. Time taken, no of errors, and number of omissions and commissions were noted to ascertain the subject's information processing speed, impulsivity, and distractibility respectively. Omissions are indicative of distractibility 
and errors are indicative of impulsivity. Both greater than are indicative of deficits in attention.

- PGI Memory Scale for Children9: This scale is developed by Kohli et al. ${ }^{9}$ It is designed to assess various domains of verbal and non-verbal memory. It assesses 10 domains of memory namely remote memory, recent memory, mental balance, digit span, delayed recall, immediate recall, retention for similar pairs, retention for dissimilar pairs, visual retention, and recognition. The scores of each subtest are compared with the mean norms of normal children from the manual.

- PGI Memory Scale for Adults ${ }^{10}$ : This scale is developed by Prashad and Wig. ${ }^{10}$ It is designed to assess various domains of verbal and non-verbal memory. It assesses ten domains of memory namely remote memory, recent memory, mental balance, digit span, delayed recall, immediate recall, retention for similar pairs, retention for dissimilar pairs, visual retention, and recognition. This scale was administered on children of higher age group since memory scale for children has norms only till 12 years of age.

- Developmental Bender Gestalt Test ${ }^{11}$ : The Developmental Bender Gestalt Test consists of nine designs and the task of the subject is to draw the designs on a blank sheet placed horizontally. The subject is instructed not to rotate the page and if he tries to rotate the card given, then he is allowed to do so and then again the card is placed horizontally right above the page. The revised scoring manual has been used in this study. Drawings indicative of a mental age, which is below more than 2 years of the chronological age of the child, is suggestive of deficits in perceptual motor functions. Each drawing can be assessed for errors, such as integration, distortion, rotation, and perseveration. The test is designed for children up to the age of 11 years.

- Bender Visuomotor Gestalt Test ${ }^{12}$ : The Bender Visuomotor Gestalt Test is a psychological test developed by Bender. ${ }^{12}$ This test is used to evaluate visual motor maturity to screen for developmental disorders or assess neurological function or brain damage. It consists of nine designs and the subject has to replicate the designs of the cards on a blank paper placed horizontally. This test assesses the drawings of the subject on errors, such as distortion, perseveration, rotation, partial rotation, concretism, abbreviation, overlap, closure, and point of contact. An error score of 0 to 4 is indicative of no dysfunction, an error score of 5 to 8 is indicative of a dysfunction rating of 1 , and an error beyond 9 up to 34 is indicative of a dysfunction rating of 2 . This test was administered on children above 11 years of age.

- Brigance Basic Academic Skills List ${ }^{13}$ : On Brigance Basic Academic Skills the child is assessed for the concept of colors, visual discrimination, gross motor skills, fine motor skills, concept of body parts and body image, verbal fluency, ability to follow a sequence of verbal instructions, articulation of sounds, identification of alphabets in English both in upper and in lower case, ability to reproduce counting 1 to 20 by rote both verbally and in written, ability to reproduce English alphabets both in upper and in lower case by dictation. This is a 24-item scale.

- NIMHANS Index of Specific Learning Disabilities ${ }^{7}$ : This is a well-accepted and widely used assessment tool for learning disabilities. It consists of two levels, i.e., level I consists of assessment of children up to the biological age of 5 to 7 years on domains of visual discrimination, auditory discrimination, visual memory, auditory memory, auditory behavior, sequencing of alphabets and numbers, ability to reproduce alphabets both in upper and in lower case. Level II of the test assesses the subject on reading and comprehension skills, arithmetic, writing, copying, and spelling skills. The basic principle to assess disability in Level II skills is to evaluate the child below two levels of his current grade, i.e., if the child is currently studying in standard VI then to ascertain disability for him/her, he/ she should not be able to perform the task standard III and standard IV.

- Malin's Intelligence Scale for Indian Children ${ }^{14}$ : This is an intelligence scale adapted from Wechsler Intelligence Scale for Children suiting the Indian setup. It is designed for age group 6 to 15 years and assesses the subjects on six verbal scales and five performance scales. However, for the study purposes only six subtests have been used, i.e., four verbal scales namely information, general comprehension, arithmetic and digit span, and two performance scales namely picture completion and block design. It consists of specific norms for each age group for each subtest based on test quotients.

- Bhatia Short Scale (BSS) ${ }^{15}$ : Bhatia Battery of Performance test is a measure of intelligence and is one among the most widely used performance tests of intelligence. It has norms for both literate and illiterate population within the age range of 11 to 16 years. It consists of five subtests namely: Koh's Block Design test, Pass Along Test, Pattern Drawing Test, Immediate Memory for Sounds and Picture Construction Test. However, the Short Battery consists of Koh's block design test and Pass Along test and it was found to be as sensitive as the full battery. It has standard scoring procedure and good reliability and validity.

- Verbal Adult Intelligence Scale ${ }^{16}$ : Verbal Adult Intelligence Scale (VAIS) is the Indian adaptation of the verbal scales of Wechsler Adult Intelligence Scale developed by Pershad and Verma, ${ }^{16}$ though the 
Profile of Deficits on Assessment Battery in Children

adaptation consists of only four subscales namely: Information, Digit Span, Arithmetic, and Comprehension. The VAIS is designed for adult subjects in the age range of 18 and above. It yields test quotients separately for all four subtests and a mean of all four test quotients yields a verbal quotient. The test has separate norms for males and females of different ages and educational levels.

\section{PROCEDURE}

Children within the age range of 10 to 18 years who had come to seek help regarding difficulties in academics either through school referral or parental observation were first registered in the CAP clinic or Adult Psychiatry Clinic of the department and then were referred for an IQ assessment to the Psychology Division. The children were made to sit in a quite atmosphere in psychology division and were assessed for IQ. Children up to the age of 15 years 11 months were evaluated on Malin's Intelligence Scale for Indian Children (MISIC) and subjects above the age of 15 years and 11 months were assessed on Bhatia Short Scale (BSS) and VAIS. Further subjects with IQ > 70 who were referred for SLD assessment were assessed on the following:

- NIMHANS battery-Level I (5-7 years), Level II (8-12 years)

- Brigance Basic Academic skills

- Attention (Speed and Accuracy Test)

- Memory

- Perceptual-motor functions.

Children up to the age of 12 years were assessed on PGI Memory Scale for Children ${ }^{9}$ and children above 12 years were assessed on PGI memory scale for adults ${ }^{10}$ since the norms for child version are only available till 12 years. Similarly children up to the age of 11 years were assessed on Developmental Bender Gestalt test and beyond the age of 12 were assessed on Bender Visual Motor Gestalt Test.

The tests were administered individually on each patient in the afternoon slot comprising of three to four sessions on an average. Each session was of 1 to $1 \frac{1}{2} 2$ hours.

\section{Ethical Considerations}

Strict confidentiality was maintained and nonwillingness to participate in the study did not result in any change in treatment. Parents were informed regarding the details of the procedure and that it is a detailed assessment so it will be time consuming.

\section{RESULTS}

The mean age of the patients was 13.5 years out of the total sample $(n=20)$. Males were $15(75 \%)$ and females
Table 1: Educational status of patients $(n=20)$

\begin{tabular}{ll}
\hline Education & Frequency (\%) \\
\hline 1st to 3rd class & $1(5)$ \\
4th to 8th class & $12(60)$ \\
9th and above & $7(35)$ \\
\hline
\end{tabular}

were $5(25 \%)$ in number. The education profile is depicted in Table 1.

To summarize the results, males outnumber females:

- About $40 \%$ of children were found to be deficient in basic academic skill, i.e., reproducing English alphabet both in writing and orally by rote with errors exhibiting errors, such as omissions and missequencing (Table 2).

- About $15 \%$ were also unable to correctly count 1 to 100 indicating a need to focus on teaching the basics during the remedial process (Tables 2 and 3 ).

- About $60 \%$ of the children have working memory deficits and are unable to do serial subtraction (Table 4).

- About $45 \%$ children have deficits in new learning and $35 \%$ have deficits in recent memory (Tables 4 and 5).

- Both visual memory and auditory memory were found to be prominently impaired in about half of the

Table 2: Pattern of deficits in basic academic skills $(n=20)$

\begin{tabular}{lll}
\hline Academic skills & Adequate & Inadequate \\
\hline Counting 1-100 by rote & $17(85 \%)$ & $3(15 \%)$ \\
Articulation of sounds & $16(80 \%)$ & $4(20 \%)$ \\
Alphabets A-Z by rote & $12(60 \%)$ & $8(40 \%)$ \\
Verbal fluency & $12(60 \%)$ & $8(40 \%)$ \\
Auditory memory & $9(45 \%)$ & $11(55 \%)$ \\
Visual memory & $10(50 \%)$ & $10(50 \%)$ \\
Verbal expression & $17(85 \%)$ & $3(15 \%)$ \\
Written expression & $6(30 \%)$ & $14(70 \%)$ \\
Spelling skills & $4(20 \%)$ & $16(80 \%)$ \\
Comprehension & $7(35 \%)$ & $13(65 \%)$ \\
\hline
\end{tabular}

Table 3: Frequent errors observed in arithmetic $(n=20)$

\begin{tabular}{ll}
\hline Errors & Frequency (\%) \\
\hline Difficulty in dodging tables & $3(15)$ \\
Difficulty in borrowing and carry over & $5(25)$ \\
Difficulty in fractions & $3(15)$ \\
Difficulty in the concept of unitary method & $1(05)$ \\
Difficulty in the concept of zero & $1(05)$ \\
Difficulty in graded division and fractions & $2(10)$ \\
Difficulty in graded arithmetic & $5(25)$ \\
\hline
\end{tabular}

Table 4: Pattern of deficits in memory $(n=20)$

\begin{tabular}{lllll}
\hline $\begin{array}{l}\text { Degree } \\
\text { of deficit }\end{array}$ & $\begin{array}{l}\text { Mental bal. } \\
\text { freq (\%) }\end{array}$ & $\begin{array}{l}\text { New learning } \\
\text { freq (\%) }\end{array}$ & $\begin{array}{l}\text { Remote } \\
\text { memory } \\
\text { freq (\%) }\end{array}$ & $\begin{array}{l}\text { Recent } \\
\text { memory } \\
\text { freq (\%) }\end{array}$ \\
\hline Mild & $4(20)$ & $8(40)$ & $3(15)$ & $6(30)$ \\
Moderate & $6(30)$ & $1(5)$ & 0 & $1(5)$ \\
Severe & $2(10)$ & 0 & $5(25)$ & 0 \\
Average & $8(40)$ & $11(55)$ & $12(60)$ & $13(65)$ \\
\hline
\end{tabular}


Table 5: Pattern of deficits in attention $(n=20)$

\begin{tabular}{ll}
\hline Areas & Frequency (\%) \\
\hline Distractibility & $10(50)$ \\
Auditory deficit & $5(25)$ \\
Short attention + distractibility & $4(20)$ \\
No deficit & $1(5)$ \\
\hline
\end{tabular}

Table 6: Frequency of disability combinations $(n=20)$

\begin{tabular}{ll}
\hline Disability combinations & Frequency (\%) \\
\hline Reading + writing & 0 \\
Reading + arithmetic & $7(35)$ \\
Reading + spelling & $1(5)$ \\
Writing + arithmetic & 0 \\
Writing + spelling & 0 \\
Arithmetic + spellings & $5(25)$ \\
Reading + writing + arithmetic + spellings & $5(25)$ \\
Reading + writing + arithmetic & 0 \\
Reading + arithmetic + spellings & $1(5)$ \\
Spellings & $1(5)$ \\
\hline
\end{tabular}

learning disabled children of the study leading to a subsequent difficulty in retention (Tables 4 and 5).

- Dyscalculia seemed to be the most prevalent, found in $90 \%$ of the children with other combinations, followed by dyslexia found in $70 \%$ of the children with other combinations The frequency of disability combinations is detailed in Table 6.

- Learning disabled children had a difficulty in the conversion of their thoughts into written form. About $70 \%$ of the children in the study had inadequate written expression even though $85 \%$ had adequate verbal expression (Table 7).

- About $45 \%$ children have been found to have deficits in perceptual motor skills (Table 8).

- About $65 \%$ children have inadequate comprehension skills thereby indicating that even though the children are able to read they are not able to comprehend the content of what they are reading (Table 9).

- About $80 \%$ of the children had inadequate spelling skills with the primary error as the inability to use phonetic cues

\section{DISCUSSION}

The ability to learn is the basis of academic performance and any factor that hampers the academic performance could be a matter of concern for both parents and teachers having a direct implication on children. The emergence of learning disorders follows a different path for every different child. It can show itself in subtle signs at an early age or gradually appear when a child starts formal education or even later when a child starts exhibiting
Table 7: Frequent writing errors $(n=20)$

\begin{tabular}{ll}
\hline Writing errors & Frequency (\%) \\
\hline Missing out letters & $2(10)$ \\
Adding letters, wrong capitals & $2(10)$ \\
Grammatical errors & $3(15)$ \\
Adding letters, wrong capitals, grammatical & $13(65)$ \\
errors & \\
\hline
\end{tabular}

Table 8: Pattern of deficits in perceptual motor functions $(n=20)$

\begin{tabular}{ll}
\hline Degree of deficit & Frequency (\%) \\
\hline Mild & $2(10)$ \\
Moderate & $4(20)$ \\
Severe & $3(15)$ \\
No dysfunction & $11(55)$ \\
\hline
\end{tabular}

Table 9: Frequent reading errors $(n=20)$

\begin{tabular}{ll}
\hline Reading errors & Frequency (\%) \\
\hline Guessing words & $4(20)$ \\
Ignoring punctuations, reading word by word, & $2(80)$ \\
$\begin{array}{l}\text { omitting words, inability to use phonetic cues, } \\
\text { spelling out words }\end{array}$ & \\
\hline
\end{tabular}

deficits gradually in later years in catching up with age mates in academics.

In our study, the sample of mixed type of learning disability children comprised of maximum number of cases of dyscalculia and dyslexia being comorbid. Literature also shows a prevalence of mixed disabilities more than the single disability. ${ }^{17}$ Previously, it was estimated that as many as $90 \%$ of children with learning disabilities have reading difficulties and even the low estimates are $60 \% .{ }^{18}$ Further, it has been reported that most children diagnosed early as reading disabled will eventually display a serious deficiency in arithmetic. ${ }^{19}$ On similar lines, when exploring the co-occurrence of both dyscalculia and dyslexia and by doing a regression analysis it was found that in a series of arithmetic problems $14 \%$ of the variance could be explained by performance affected by reading skills, $8 \%$ attributable to computational skills, and $32 \%$ attributable to joint variance..$^{20}$ An alternative hypothesis to explain comorbid reading and maths deficits relate to overall deficits in verbal short-term or long-term memory retrieval. ${ }^{21}$

On similar lines, in our study we have also found verbal memory deficits in the domain of new learning. In an attempt to explore the specific mechanisms underlying the verbal memory deficits in dyslexia, it was found that less efficient encoding mechanisms result in deficient encoding of new information in reading disabled children. ${ }^{22}$ However, they have reported that these children have adequate retention and retrieval. In our results, we have also found deficits in remote memory and recent memory in 35 to $40 \%$ of the children. This finding seems to replicate the previous findings, which also point that dyslexic children have deficits in long-term verbal 
memory storage and are less capable of acquisition of new information. ${ }^{23}$

Deficits in visual and auditory memory in half the number of cases are also being reported. Visual and auditory processing are the two most common areas of difficulties in learning disability, suggesting further that reading and maths are two subjects where accurate perception and understanding of spatial relationships is important. Both the subjects rely on the use of symbols letters, numbers, signs, punctuation marks, and so forth. Visual memory deficits can interfere with the learning process as something which was learnt today could fade out the next day. ${ }^{24}$

Similarly, working memory deficits were found in about $60 \%$ of the children while doing serial subtraction. It has been found that deficiencies in the domain of spatial working memory and some aspects of executive functioning are present in children with arithmetic disability. ${ }^{25}$ Similarly it was earlier proposed that along with counting knowledge and strategy choice for solving a problem, working memory deficits may also lead to failure of long-term memory representation of basic facts. ${ }^{26}$ Earlier in a more specific study reading and arithmetic disabled group has been reported to be affected by a general working memory impairment, i.e., both counting span and sentence span being deficient, whereas only arithmetic disabled group had a domain-specific working memory deficit, i.e., on counting span. ${ }^{27}$ The common arithmetic errors found in our sample, such as difficulty on dodging, carry over, borrowing, and graded arithmetic could be attributed to working memory deficits. Numerous studies have demonstrated that working memory is related to differences in performance on arithmetic. ${ }^{28-30}$ The visuospatial sketch pad has been reported to be involved in multi digit problems where visual and spatial knowledge of column positioning is required, ${ }^{31}$ such as graded arithmetic functions. On similar lines another component of working memory, i.e., phonological loop appears to be important in counting and in holding information in complex calculations, ${ }^{32}$ such as fractions and simple counting. ${ }^{33}$ The role of central executive of working memory has also been reported in switching retrieval strategies which are important in graded multiplication where after multiplication addition of numbers is also required to be done. ${ }^{34}$

Learning disabled children also show deficits, such as poor handwriting, omissions while writing when copying from a book or the board, inability to write in a straight line. Such errors can be attributed to deficits in perceptual motor skills. Perceptual motor skills require the ability to translate visual perception into motor functioning involving motor control, motor accuracy, motor coordination, and psychomotor speed. It has been reported that visual motor coordination was the most significant predictor of handwriting performance. ${ }^{35}$ In our study also we have found deficits in perceptual motor functions in $45 \%$ of the children ranging from mild to severe. Similar reports claim that $90 \%$ of the learning disabled children have deficits in perceptual motor functions, which also affects their fine motor skills, such as cutting with scissors, pasting, coloring. ${ }^{36}$ Thus writing errors found in our sample, such as omissions of letters, addition of letters, and wrong capitals could partly be attributed to perceptual motor deficits and to working memory deficits.

About $70 \%$ of the children could adequately express themselves verbally; however, $80 \%$ could not transform this verbal expression into written form. It has previously been reported that children find producing a written narrative significantly more difficult than oral narrative ${ }^{37}$ and the written mode takes up more cognitive resource. ${ }^{38}$ Subcomponents of language, i.e., grammar, phonology, lexicon, and pragmatics have also been reported to affect the written expression. ${ }^{39}$ This difficulty in conversion of verbal expression to written expression could further be attributed to word finding difficulties. It has been observed that many students with learning disabilities retrieve words slowly and word finding problems could be lifelong sources of difficulty in reading, learning, and expressive language. ${ }^{40}$ Word finding difficulties have also been associated with reading difficulties. ${ }^{41}$ Phonological retrieval deficits have been found to co-occur with reading difficulties $^{42}$ and besides all other subtle oral language difficulties word finding difficulties are one symptom. ${ }^{43}$ However, latest research has shown that slow learners with reading difficulties who also have word finding difficulties are able to successfully identify words in silent reading recognition tasks, but missed them in oral reading. ${ }^{44,45}$

The strength of this study includes exhaustive and in-depth application of culture-specific instruments in a homogenous hospital-based sample of mixed type of SLD. And the clinical diagnosis was established by a consultant psychiatrist after detailed workup and thorough interview.

However, the limitations of the study are that other neuropsychological assessments for executive functions were not done and the sample size is small.

To conclude, this study highlights the fact that emphasis should be laid on explaining the concepts to children using concrete examples before proceeding onto abstract concepts due to difficulties in conversion of verbal thought to written expression. Subtle signs of cognitive deficits can be identified early, such as poor handwriting, word finding difficulties, difficulties in identifying mathematical signs, poor sentence span, deficits in following a sequence of verbal instruction, and poor number span, 
which should be taken seriously as few possible markers of a probable learning problem. It is not only the health professionals but the parents and family members who sometimes first suspect such deficits at an early stage and seek help so as to prevent its long-term academic, social, and emotional consequences.

\section{REFERENCES}

1. Ministry of Education. Supporting students with learning disabilities—a guide for teachers. British Columbia: Ministry of Education; 2011.

2. Sartorius N, Kaelber CT, Cooper JE, Roper MT, Rae DS, Gulbinat W, Ustün TB, Regier DA. Progress towards achieving a common language in psychiatry. Results from the field trials of the clinical guidelines accompanying the WHO classification of mental and behavioural disorders in ICD-10. Arch Gen Psychiatry 1993 Feb;50(2):115-124.

3. National Institute for the Mentally Handicapped. Educating children with learning problems in primary schools: resource book for teachers. Secunderabad: National Institute for the Mentally Handicapped; 2003.

4. Crealock, C.; Kronick, D. Children and young people with specific learning disabilities. Guide for special education no. 9. Paris: UNESCO Gallaudet university Press; 1993.

5. Padhy SK, Goel S, Das SS, Sarkar S, Sharma V, Panigrahi M. Prevalence and patterns of learning disabilities in school children. Indian J Pediatr 2016 Apr;83(4):300-306.

6. Ariel, A. Education of children and adolescents with learning disabilities. New York: Maxwell Macmillan International; 1992.

7. Kapur, M.; John, A.; Rozario, J.; Oommen, A.; Uma, H. Assessment of specific learning disabilities. In: Hirisave U, Oommen A, Kapur M, editors. Psychological assessment of children in the clinical setting. Bengaluru: Vinayaka Offset Printers; 2002.

8. Kapoor, SD. Speed and accuracy test. New Delhi: Psychocentre; 1972.

9. Kohli A, Mohanty M, Malhotra R, Verma SK. Measurement of memory in children: construction of a simple clinical tool in Hindi. Behav Med J 1998;1(1):34-42.

10. Prashad, D.; Wig, NN. PGI memory scale (revised manual) PGIMER. Chandigarh: National Psychological Corporation; 1988.

11. Koppitz, EM. The Bender Gestalt test for young children. New York: Grune \& Stratton, Inc; 1963.

12. Bender L. Visual-Motor Gestalt Testand its clinical use. American Orthopsychiatric Association, Research monographs, no. 3. New York: American Orthopsychiatric Association; 1938.

13. Brigance, $\mathrm{AH}$. Brigance diagnostic inventory. North Billerica (MA): Curriculum Associate Inc; 1977.

14. Malin, AJ. Manual for Malin's Intelligence Scale for Indian Children (MISIC). Lucknow: Indian Psychological Corporation; 1969.

15. Verma, SK.; Pershad, D.; Malhotra, A.; Mahajan, A. Manual for the revised Bhatia's short battery of performance tests of intelligence for adults. Agra: National Psychological Corporation; 1971.

16. Pershad, D.; Verma, SK. Translation and Adaptation of WAIS-R Verbal Scale in Hindi. In: Pershad D, Verma SK, editors. The concept and assessment of intelligence. Agra: National Psychological Corporation; 1988.
17. Krishna, RJ.; Oommen, A.; Rao, SL. A multidimensional analysis of learning disability. Unpublished $\mathrm{PhD}$ in Clinical Psychology thesis submitted to National Institute of Mental Health and Neurosciences, Bengaluru. 2008.

18. Bender, WN. Learning disabilities: characteristics, identification and teaching strategies. 4th ed. Boston (MA): Allyn \& Bacon; 2001.

19. Ackerman PT, Anhalt JM, Dykman RA. Arithmetic automatization failure in children with attention and reading disorders: associations and sequelae. J Learn Disabil 1986 Apr;19(4): 222-232.

20. Muth KD. Solving arithmetic word problems: role of reading and computational skills. J Educ Psychol 1984 Apr;76(2): 205-210.

21. Brandys, CF.; Rourke, BF. Differential memory abilities in reading and arithmetic-disabled children. In: Rourke BF, editor. Neuropsychological validation of learning disability subtypes. New York: Guilford; 1991. pp. 73-96.

22. Kramer JH, Knee K, Delis DC. Verbal memory impairments in dyslexia. Arch Neuropsychol 2000 Jan;15(1):83-93.

23. Nelson HE, Warrington EK. An investigation of memory functions in dyslexic children. Br J Psychol 1980 Nov;71(4):487-503.

24. National Centre for Learning Disabilities (NCLD). Visual and auditory processing disorders. Washington (DC): NCLD; 1999. [cited 2015 Aug 30]. Available from: http:/ /www.ldonline. org/article/6390?theme=print.

25. McLean JF, Graham JH. Working memory impairments in children with specific arithmetic learning difficulties. J Exp Child Psychol 1999 Nov;74(3):240-260.

26. Geary DC, Brown SC, Samanayake VA. Cognitive addition: a short longitudinal study of strategy choice and speed-ofprocessing differences in normal and mathematically disabled children. Dev Psychol 1991 Sep;27(5):787-797.

27. Siegel LS, Ryan EB. The development of working memory in normally achieving and subtypes of learning disabled children. Child Dev 1989 Aug;60(4):973-980.

28. Swanson HL. Working memory in learning disability subgroups. J Exp Child Psychol 1993 Aug;56(1):87-114.

29. Swanson HL. Short-term memory and working memory: do both contribute to our understanding of academic achievement in children and adults with learning disabilities. J Learn Disabil 1994 Jan;27(1):34-50.

30. Bull R, Johnston RS. Children's arithmetic difficulties: contributions from processing speed, item identification, and short-term memory. J Exp Child Psychol 1997 Apr;65(1):1-24.

31. Heathcote D. The role of visuo-spatial working memory in the mental addition of multi-digit addends. Curr Psychol Cogn 1994 Apr;13(2):207-245.

32. Logie RH, Gilhooly KJ, Wynn V. Counting on working memory in arithmetic problem solving. Mem Cognit 1994 Jul;22(4):395-410.

33. Logie $\mathrm{RH}$, Baddeley $\mathrm{AD}$. Cognitive processes in counting. J Exp Psychol 1987 Apr;13(2):310-326.

34. Baddeley A. Exploring the central executive. Quart J Exp Psychol 1996;49A(1):5-28

35. Sovik, N. Developmental cybernetics of handwriting and graphic behaviour. Boston (MA): Universitetsforlaget; 1975.

36. Darcy, AU. Neurological rehabilitation. 4th ed. St. Louis (MO): C.V Mosby Company; 2001. p. 319.

37. Gillam RB, Johnston JR. Spoken and written language relationships in language learning impaired and normally achieving school-age children. J Speech Hear Res 1992 Dec;35(6):1303-1315. 
38. Bourdin B, Fayol M. Is graphic activity cognitively costly? A developmental approach. Reading Writing 2000 Dec;13(3-4): 183-196.

39. Hirsh-Pasek K, Kochanoff A, Newcombe NS, de Villiers J. Using scientific knowledge to inform preschool assessment: making the case for "empirical validity". Social Policy Rep 2005;19(1):1-9.

40. Lerner, J. Learning disabilities: theories, diagnosis and teaching strategies. 8th ed. Boston (MA): Houghton Mifflin; 2000.

41. McBride-Chang C, Manis FR. Structural invariance in the associations of naming speed, phonological awareness and verbal reasoning in good and poor readers: a test of the double deficit hypothesis. Reading Writing 1996 Aug;88(4): 323-339.

42. Catts, H.; Kamhi, A. Causes of reading difficulties. In: Catts HW, Kamhi AG, editors. Language and reading disabilities. Boston (MA): Allyn \& Bacon; 1999. pp. 95-127.

43. Murphy LA, Pollatsek A, Well AD. Developmental dyslexia and word retrieval deficits. Brain Lang 1988 Sep;35(1):1-23.

44. German DJ, Newman RS. Oral reading skills of children with oral language (word finding) difficulties. Reading Psychol 2007 Nov;28(5):397-442.

45. German, DJ.; Newman, RS. Word finding based oral reading errors. Paper presented at the International Congress of the Study of Child Language (ICSAL), Berlin, Germany; 2005. 